\title{
Metabolic syndrome among Nigerians with type 2 diabetes mellitus: a comparative study of the diagnostic criteria.
}

Taoreed Adegoke Azeez ( $\square$ adegokegalaxy@yahoo.com )

University College Hospital Ibadan https://orcid.org/0000-0003-3982-5790

Jokotade Adeleye

University College Hospital Ibadan

Omololu Adedoyin Enigbokan

University College Hospital Ibadan

Bolaji Adejimi

University College Hospital Ibadan

John Sunday Oladapo

University College Hospital Ibadan

\section{Research Article}

Keywords: Metabolic syndrome, diabetes mellitus type 2, comparative study, Nigeria, cardiovascular risk, diagnosis criteria

Posted Date: August 14th, 2021

DOI: https://doi.org/10.21203/rs.3.rs-795474/v1

License: (1) This work is licensed under a Creative Commons Attribution 4.0 International License. Read Full License 


\section{Abstract}

\section{Background}

Metabolic syndrome is associated with increased cardiovascular death. The objectives of this study were to find the frequency of metabolic syndrome among Nigerians with type 2 diabetes and to compare the modified NCEP ATP III criteria and the IDF criteria

\section{Methods}

The study involved 134 participants. Sixty-seven were cases with type 2 diabetes while the rest were the controls without type 2 diabetes. Ethical approval was granted by the institution's ethics review committee. Anthropometric, clinical and laboratory parameters were obtained using standard protocols. Data were analyzed with SPSS version 22. Means were compared with Student's $t$ test while proportions were compared with the Pearson's chi square. Point biserial correlation was used to determine the association between the dichotomous variables and interval variables. Agreement between the criteria was tested with the Cohen's kappa test.

\section{Results}

Type 2 diabetes was associated with a higher prevalence of hypertension and truncal obesity. The frequency of metabolic syndrome was lower with the IDF criteria compared with the modified NCEP criteria (65.7\% vs $71.6 \%)$. Although there was a strong agreement between the IDF and the modified NCEP criteria ( $k=0.862 ; p<0.0001$ ) yet, the IDF criteria missed $8.3 \%$ of diabetic individuals diagnosed with metabolic syndrome by the modified NCEP criteria. Cardiovascular risk is better predicted when the modified NCEP criteria were used to diagnose metabolic syndrome.

\section{Conclusion}

Metabolic syndrome is very common among Nigerians with type 2 diabetes and it is better diagnosed with the modified NCEP ATP III criteria.

\section{Introduction}

A syndrome is a constellation of symptoms and signs attributed to a disease. ${ }^{1}$ It is a term that suggests that the occurrence of certain clinical manifestations are not just due to chance. In 1988, an American Endocrinologist, Gerald Reaven, described a cluster of clinical features which were considered to be linked together and insulin resistance was posited to be the central theme of the cluster. ${ }^{2}$ He called the cluster 'syndrome $X$ '. Since then, there has been disagreement among researchers and experts on the definition, nomenclature and criteria for the syndrome. ${ }^{1}$ Apart from insulin resistance, the other components of the syndrome include elevated blood pressure, dyslipidaemia, glucose intolerance and central obesity. ${ }^{3}$ 
In 1998, the World Health Organization (WHO) Consultation Group came up with a definition based on the presence of obesity and certain metabolic abnormalities. ${ }^{4}$ The syndrome became more commonly referred to as 'metabolic syndrome'. The WHO criteria for the diagnosis of metabolic syndrome are shown in Table 1 below. ${ }^{4}$

Table 1

WHO criteria for metabolic syndrome

\section{Criteria}

1. Glucose intolerance, impaired glucose tolerance, or diabetes mellitus and/or insulin resistance.

2. Blood pressure $\geq 140 / 90 \mathrm{mmHg}$

3. Waist-hip ratio $>0.9$ in males or $>0.85$ in females and/or body mass index $\geq 30 \mathrm{~kg} / \mathrm{m}^{2}$

4. Plasma triglycerides $\geq 150 \mathrm{mg} / \mathrm{dl}$ and/or high density lipoproteincholesterol $<35 \mathrm{mg} / \mathrm{dl}$ in men or $<39 \mathrm{mg} / \mathrm{dl}$ in women

5. Urinary albumin excretion $\geq 20 \mu \mathrm{g} / \mathrm{min}$ or albumin-creatinine ratio $\geq$ $30 \mu \mathrm{g} / \mathrm{mg}$
Requirement for diagnosis

(1) and any other 2 are required for the diagnosis.

In 1999, shortly after the publication of the WHO criteria for metabolic syndrome, the European Group for the Study of Insulin Resistance (EGIR) reported their own criteria for metabolic syndrome. ${ }^{5}$ The term favoured by the group was 'insulin resistance syndrome'. The EGIR required an elevated plasma insulin > 75th percentile before the diagnosis of metabolic syndrome could be made. ${ }^{4}$ In addition, the focus was on abdominal obesity while the presence of diabetes and microalbuminuria were dropped. ${ }^{6}$

In 2001, in the executive summary of the third report of the National Cholesterol Education Program on the detection, evaluation and treatment of high blood cholesterol in adults - adults treatment panel III (NCEP ATP III), the criteria for the diagnosis of metabolic syndrome were described. ${ }^{7}$ The panel did not believe that insulin resistance was mandatory for the development of metabolic syndrome, rather, abdominal obesity was seen as the main culprit hence, they favoured the term 'metabolic syndrome'. 4 Also, waist circumference was adopted to quantify abdominal obesity instead of the waist-hip ratio. Moreover, plasma triglycerides (TG) and high density lipoprotein cholesterol (HDL-C) were considered as independent criteria. The NCEP ATP criteria are depicted in Table 2 below. ${ }^{8}$ 
Table 2

NCEP ATP III criteria for metabolic syndrome

\section{Criteria}

Requirement for diagnosis

1. Fasting plasma glucose $>100 \mathrm{mg} / \mathrm{dl}^{*}$ or previously diagnosed with type 2 diabetes

2. Systolic blood pressure $>130 \mathrm{mmHg}$ and/or diastolic blood pressure > $85 \mathrm{mmHg}$ or on treatment for previously diagnosed hypertension.

3. Waist circumference $\geq 102 \mathrm{~cm}$ in males or $\geq 88 \mathrm{~cm}$ in females.

4. Plasma triglycerides $\geq 150 \mathrm{mg} / \mathrm{dl}$

5. HDL-C $<40 \mathrm{mg} / \mathrm{dl}$ in men or $<50 \mathrm{mg} / \mathrm{dl}$ in women

*- In the original criteria, FPG value required for diagnosis was $110 \mathrm{mg} / \mathrm{dl}$ but it was later reduced to $100 \mathrm{mg} / \mathrm{dl}$ following a similar reduction by the American Diabetes Association. ${ }^{9}$

In 2005, due to the profuse controversies generated from the definition of metabolic syndrome by various bodies, the International Diabetes Federation (IDF) came up with a global consensus definition for metabolic syndrome. ${ }^{10}$ It also established central obesity as the focal point in metabolic syndrome. Waist circumference was also used in quantifying central obesity but the cut-off points became ethnic- and gender-specific. The Europoids cut off is adopted for Africans and it is what is shown in Table 3 below. ${ }^{4}$

Table 3

IDF criteria for metabolic syndrome

\section{Criteria}

1. Waist circumference $\geq 80 \mathrm{~cm}$ in males or $\geq 94 \mathrm{~cm}$ in females.*

2. Systolic blood pressure $>130 \mathrm{mmHg}$ and/or diastolic blood pressure > $85 \mathrm{mmHg}$ or on treatment for previously diagnosed hypertension

3. Fasting plasma glucose $>100 \mathrm{mg} / \mathrm{dl}$ or previously diagnosed with type 2 diabetes

4. Plasma triglycerides $\geq 150 \mathrm{mg} / \mathrm{dl}$

5. HDL-C $<40 \mathrm{mg} / \mathrm{dl}$ in men or $<50 \mathrm{mg} / \mathrm{dl}$ in women

*- The waist circumference is dependent on ethnicity. The figure for Africans was quoted.

Following the publication of the IDF criteria, the modified NCEP ATP III criteria came on board. ${ }^{11}$ The modified version agreed with the IDF criteria and the fixed waist circumference shown in Table 2 was dropped for the ethnic-based waist circumference. However, despite the modification, abdominal obesity continues to be seen as a component rather than a prerequisite for the diagnosis of metabolic syndrome and this distinguishes the modified NCEP ATP III criteria from the IDF criteria. ${ }^{11}$ 
Insulin resistance is defined as the attenuated biological response to the usual amount of insulin. ${ }^{12}$ Despite the various controversies, many authors still aver that insulin resistance is the underlying mechanism of insulin resistance which results from an interplay of genetic and environmental factors. ${ }^{13}$ Previous studies have also shown an association between insulin resistance and the various components of metabolic syndrome ${ }^{14}$ Insulin resistance cannot be directly measured clinically but there are surrogate markers for it. ${ }^{15}$ Among the surrogate markers of insulin resistance, the homeostatic model of assessment of insulin resistance (HOMA-IR) is the most commonly quoted. ${ }^{16}$

Metabolic syndrome is a cluster of cardiovascular risk factors and is therefore associated with increased cardiovascular death. ${ }^{17}$ Cardiovascular risk is said to be $50-60 \%$ higher in people with metabolic syndrome compared with those without metabolic syndrome. ${ }^{18}$ There are different cardiovascular risk calculators that have been documented in the literature. In the primary prevention of atherosclerotic cardiovascular disease, risk estimation is of crucial importance. ${ }^{19}$ The American Heart Association/American College of Cardiology (AHA/ACC) Atherosclerotic Cardiovascular Disease (ASCVD) risk score predicts 10-year cardiovascular risk of heart disease or stroke and is validated in many ethnic groups. ${ }^{20}$

\section{Objectives}

The study was aimed at

1. Comparing the profile of cardiovascular risk factors between Nigerians with and without type 2 diabetes mellitus,

2. Comparing the prevalence of metabolic syndrome among Nigerians with type 2 diabetes using the modified NCEP ATP III and IDF criteria,

3. Determining the association between metabolic syndrome diagnosed with the modified NCEP ATP III and IDF criteria among Nigerians with type 2 diabetes and HOMA-IR, waist circumference and ASCVD risk score, and

4. Estimating the extent of agreement between the modified NCEP ATP III and IDF criteria for the diagnosis of metabolic syndrome among Nigerians with type 2 diabetes

\section{Methods}

The study design was an analytical cross-sectional study with a control group. One hundred and thirtyfour participants were involved in the study. The cases were 67 individuals previously diagnosed with type 2 diabetes mellitus and the controls were also 67 individuals without type 2 diabetes mellitus. The cases were the individuals selected by systematic random sampling from the type 2 diabetes mellitus patients attending the diabetes clinic of a public tertiary hospital in Southern Nigeria. The controls were apparently healthy individuals without type 2 diabetes mellitus selected randomly from the community. Potential controls were asked if they had ever been diagnosed with type 2 diabetes and were also 
screened for type 2 diabetes with fasting plasma glucose and glycated haemoglobin. Only those confirmed as not having type 2 diabetes were recruited into the study.

Inclusion criterion for the cases was prior diagnosis with type 2 diabetes (more than 6 months). Exclusion criteria were type 1 diabetes mellitus, on-going active weight loss programme, metabolic decompensation, hospital admission in the preceding 3 months to recruitment, pregnancy and prior diagnosis of cardiovascular disease (stroke, myocardial infarction and peripheral arterial disease). Inclusion criterion for the controls was the absence of type 2 diabetes mellitus. The exclusion criteria were similar to those of the cases earlier stated.

The institution ethics review committee (with the reference number NHREC/05/01/2008a) granted ethical approval for the study. The reference number of the approval is $U I / E C / 17 / 0284$. After thorough explanation, the potential participants gave written consent for participation in the study and publication of the findings before they were recruited into the study.

Waist circumference was measured with an inelastic tape measure as the horizontal abdominal girth at the midpoint between the lowest rib and the iliac rest after tidal expiration. The WHO standard protocol on waist circumference measurement was carefully followed. ${ }^{21}$ Using the American Heart Association blood pressure measurement guidelines, each participant had his systolic blood pressure (SBP) as well as the diastolic blood pressure (DBP) measured with a sphygmomanometer (Accoson brand, made in England).

A fasting blood ample was obtained from each participant. Fasting plasma glucose was determined using the enzymatic method run on an Autochemistry analyzer (Accurex Biomedical, Mumbai, India). Fasting plasma triglyceride and HDL-C were also measured using the appropriate enzymatic method. Fasting plasma insulin was assayed using the enzyme-linked immunosorbent assay (ELISA) technique with Cell Biolab Human Insulin ELISA kit (California, USA). The recommended high performance liquid chromatography method was adopted in measuring the glycated haemoglobin ( $\mathrm{HbA1c}$ ). Automated glycohaemoglobin analyzer (Bio-Rad 220 - 0212, Hercules, California, USA) was used for this purpose.

HOMA-IR was calculated using the standard formula given below. ${ }^{22}$ Insulin resistance was defined as HOMA-IR $>2$ as defined by a previous study involving Nigerians. ${ }^{23}$

\section{See formula 1 in the supplementary files section.}

The 10-year cardiovascular risk score was determined using the ASCVD risk estimator on the American College of Cardiology website. ${ }^{24}$ ASCVD score below 5.0 was taken as 'low risk' while ASCVD score $\geq 5.0$ was taken as 'intermediate/high risk'. ${ }^{25}$ Metabolic syndrome was defined using the modified NCEP ATP III and IDF criteria respectively. 4,11

Statistical analysis was performed with the Statistical Package for Social Sciences (SPSS) version 22. Continuous variables were summarized as mean \pm standard deviation while nominal variables were summarized as frequencies and percentages. The association between the presence or absence of 
metabolic syndrome (using the modified NCEP ATP III and IDF criteria) and interval variables (ASCVD risk score, waist circumference and HOMA-IR) was determined using point biserial correlation. The means of continuous variables were compared with the independent sample student's $t$ test. The frequencies of nominal variables were compared with the Pearson's chi square test. Agreement between two dichotomous nominal variables was determined using the Cohen's kappa statistic. Cohen's kappa coefficient ( $\mathrm{K}$ ) was interpreted as shown in Table 4 below. ${ }^{26} \mathrm{~A} p<0.05$ was considered as being statistically significant.

Table 4

Interpretation of Cohen's kappa coefficient ( $\mathrm{k}$ )

\begin{tabular}{|ll|}
\hline Cohen's kappa coefficient (K) & Interpretation \\
\hline$\leq 0$ & No agreement \\
\hline $0.01-0.2$ & None to slight agreement \\
$0.21-0.4$ & Fair agreement \\
\hline $0.41-0.6$ & Moderate agreement \\
\hline $0.61-0.8$ & Substantial agreement \\
\hline $0.81-1.0$ & Almost perfect agreement \\
\hline
\end{tabular}

\section{Results}

The characteristics of the participants are shown in Table 5 below. The mean age of the cases was 53.21 \pm 9.71 and it was not significantly different from that of the controls $(p=0.792)$. The gender distribution of both the cases and the controls were the same with females accounting for $50.7 \%$. Male cases with type 2 diabetes had a higher waist circumference compared with male controls without type 2 diabetes $(p<0.0001)$ but this was not reproducible in females $(p=0.158)$. The subjects had a significantly higher SBP compared with that of the controls $(p=0.002)$.

Interestingly, this study did not show any significant difference in TG and HDL-C between cases with type 2 diabetes and controls without the disease. Insulin resistance and 10-year cardiovascular risk were significantly higher among the cases compared with those of the controls $(p<0.0001)$.

The frequency of metabolic syndrome among individuals living with diabetes was slightly higher using the modified NCEP ATP III criteria (71.6\%) than using the IDF criteria (65.7\%). As expected, irrespective of the criteria used, metabolic syndrome was significantly commoner in the participants with type 2 diabetes mellitus compared with the controls without type 2 diabetes mellitus $(p<0.0001)$.

Table 6 indicates the point biserial correlation between the presence of metabolic syndrome among the individuals with type 2 diabetes mellitus (using either the modified NCEP ATP III criteria or the IDF criteria) and HOMA-IR as well as 10-year cardiovascular risk (using the ASCVD risk score). Among Nigerians living 
with type 2 diabetes mellitus, those diagnosed with metabolic syndrome using the modified NCEP ATP III criteria were likely to have a higher ASCVD risk score $(p=0.04)$. However, this could not be said for those diagnosed with the IDF criteria. However, there was a significant association between metabolic syndrome and waist circumference irrespective of the criteria used $(p<0.0001)$

Table 7 shows the level of agreement between the diagnostic criteria for metabolic syndrome. There is almost perfect agreement between using the IDF criteria and the modified NCEP ATP III criteria in diagnosing metabolic syndrome $(\mathrm{K}=0.862 ; \mathrm{p}<0.0001)$. Also, there was a fair agreement between metabolic syndrome diagnosed with the modified NCEP ATP III criteria and the presence of intermediate/high cardiovascular risk $(k=0.213 ; p=0.029)$. 
Table 5

The characteristics of the participants

\begin{tabular}{|c|c|c|c|c|}
\hline \multirow[t]{2}{*}{ Variable } & \multicolumn{2}{|c|}{ Mean \pm SD OR Frequency (\%) } & \multirow[t]{2}{*}{ Test statistic } & \multirow[t]{2}{*}{$p$ value } \\
\hline & Case & Control & & \\
\hline Age (years) & $53.21 \pm 9.71$ & $52.94 \pm 9.96$ & $t=0.265$ & 0.792 \\
\hline Gender & $34(50.7 \%)$ & $34(50.7 \%)$ & $x^{2}=0.000$ & 1.000 \\
\hline Males & $33(49.3 \%)$ & $33(49.3 \%)$ & & \\
\hline \multicolumn{5}{|l|}{ Females } \\
\hline Waist circumference(cm) & $94.82 \pm 4.69$ & $87.91 \pm 6.40$ & $t=5.079$ & $0.000 * \star$ \\
\hline Males & $90.67 \pm 6.96$ & $87.90 \pm 8.63$ & $t=1.429$ & $0.158 * \star$ \\
\hline \multicolumn{5}{|l|}{ Females } \\
\hline SBP $(\mathrm{mmHg})$ & $126.79 \pm 18.93$ & $112.13 \pm 13.08$ & $t=3.278$ & $0.002^{\star \star}$ \\
\hline $\mathrm{DBP}(\mathrm{mmHg})$ & $80.72 \pm 11.97$ & $80.03 \pm 10.92$ & $t=0.414$ & 0.680 \\
\hline $\mathrm{FPG}(\mathrm{mg} / \mathrm{dl})$ & $113.72 \pm 15.95$ & $86.75 \pm 8.13$ & $t=8.550$ & $0.000 * \star$ \\
\hline HbA1c (\%) & $6.99 \pm 0.73$ & $4.95 \pm 0.47$ & $t=13.380$ & $0.000 * \star$ \\
\hline HDL-C (mg/dl) & $46.85 \pm 10.32$ & $48.67 \pm 9.83$ & $t=0.746$ & 0.458 \\
\hline Males & $53.36 \pm 13.32$ & $51.72 \pm 10.14$ & $t=0.168$ & 0.575 \\
\hline \multicolumn{5}{|l|}{ Females } \\
\hline Fasting TG (mg/dl) & $101.51 \pm 17.10$ & $97.58 \pm 20.01$ & $t=0.237$ & 0.813 \\
\hline Fasting insulin ( $\mu \mathrm{mol} / \mathrm{L})$ & $9.36 \pm 3.13$ & $8.13 \pm 1.46$ & $t=2.748$ & $0.008^{\star \star}$ \\
\hline HOMA-IR & $2.59 \pm 0.83$ & $1.70 \pm 0.72$ & $t=6.758$ & $0.000 * \star$ \\
\hline ASCVD risk score & $18.75 \pm 10.33$ & $3.94 \pm 3.24$ & $t=8.011$ & $0.000 * \star$ \\
\hline Frequency of MS & $48(71.6 \%)$ & $12(17.9 \%)$ & $\chi^{2}=31.561$ & $0.000 * *$ \\
\hline NCEP ATP III & $44(65.7 \%)$ & $7(10.4 \%)$ & $\chi^{2}=43.337$ & $0.000^{\star \star *}$ \\
\hline IDF & & & & \\
\hline \multicolumn{5}{|l|}{ MS - Metabolic syndrome } \\
\hline **- statistically significant & & & & \\
\hline
\end{tabular}


Table 6

Point biserial correlation between cardiovascular risk and metabolic syndrome

\begin{tabular}{|lllll|}
\hline \multicolumn{4}{|c|}{ MS with modified NCEP ATP III } & \multicolumn{2}{l|}{ MS with IDF } \\
\hline & $\mathrm{r}_{\mathrm{pb}}$ & $p$ & $\mathrm{r}_{\mathrm{pb}}$ & $p$ \\
\hline HOMA-IR & 0.014 & 0.909 & 0.030 & 0.810 \\
\hline ASCVD score & 0.251 & $0.040^{* *}$ & 0.228 & 0.063 \\
\hline Waist circumference & 0.502 & $0.000^{* *}$ & 0.589 & $0.000^{* *}$ \\
\hline \multirow{2}{*}{$* *$ - statistically significant $\mathrm{r}_{\mathrm{pb}}$ - point biserial correlation coefficient } & \\
\hline
\end{tabular}

Table 7

Level of agreement among the diagnostic criteria and cardiovascular risk

\begin{tabular}{|c|c|c|c|c|}
\hline & \multicolumn{2}{|c|}{ NCEP ATP III } & \multicolumn{2}{|l|}{ IDF } \\
\hline & $\mathbf{K}$ & $\mathrm{p}$ & $\mathrm{K}$ & $\mathrm{p}$ \\
\hline NCEP ATP III & - & - & 0.862 & $0.000 * \star$ \\
\hline IDF & 0.862 & 0.000 ** & - & - \\
\hline Insulin resistance (HOMA-IR) & 0.143 & 0.144 & 0.116 & 0.273 \\
\hline ASCVD risk categories & 0.213 & $0.029 * *$ & 0.156 & 0.080 \\
\hline
\end{tabular}

\section{Discussion}

This study showed a higher frequency of cardiovascular risk factors such as truncal obesity and elevated systolic blood pressure among individuals living with type 2 diabetes compared to the controls who did not have type 2 diabetes. In another study involving Nigerians with type 2 diabetes mellitus, the researchers posited that cardiovascular risk factors were more common among the individuals with type 2 diabetes compared with those without type 2 diabetes. ${ }^{16}$ Several authors in the past have noted this cluster of risk factors and that was the genesis of the studies on metabolic syndrome. ${ }^{27}$

Previous studies have also documented a higher frequency of elevated systolic blood pressure among individuals with diabetes compared with the general population, just as it was found in the present study. ${ }^{28,29}$ Type 2 diabetes causes arterial stiffening especially in the presence of sub-optimal metabolic control and this is believed to be one of the links between type 2 diabetes and elevated systolic blood pressure. ${ }^{30}$ Other mechanisms that have been documented as the plausible explanations for a higher frequency of elevated systolic blood pressure among individuals with diabetes are endothelial 
dysfunction, sodium retention, sympathetic over-activity, renin-angiotensin-aldosterone activation and nephropathy. ${ }^{31}$ However, as hypothesized by some authors, the relationship between type 2 diabetes and hypertension is more reciprocal than causal. ${ }^{32}$

As noted in the present study, truncal obesity, represented by weight circumference, was higher among individuals with type 2 diabetes and similar observation has been reported from previous studies. ${ }^{33}$ Abdominal distribution of fat is a better determinant of the risk of developing type 2 diabetes than the total body fat mass. ${ }^{34}$ Truncal obesity is characterized with increased inflammatory cytokines and nonesterified fatty acids as well as hormonal dysregulation which are thought to be the underlying processes leading to insulin resistance and eventually type 2 diabetes mellitus. ${ }^{35}$

Quite striking was the observation, in this study, that the HDL-C and fasting triglycerides of those with or without type 2 diabetes mellitus were not significantly different. In the general population, an epidemiological study quoted by Laakso has demonstrated that the lipid profiles of individuals with type 2 diabetes were not remarkably different from that of the general population. ${ }^{36}$ However, our study was a hospital based study and previous hospital-based studies have documented a significantly lower HDL-C and higher triglycerides (a cluster sometimes called diabetic dyslipidaemia) among individuals with type 2 diabetes. ${ }^{37,38}$ Nevertheless, Zheng et al posited that the association between hypertriglyceridemia and type 2 diabetes is better appreciated in the presence of poor glycaemic control. Since the participants in this present study had averagely good glycaemic control, evidenced by the Hba1c $(6.99 \pm 0.73 \%)$, it would not be out of place to get a triglyceride and HDL-C profile that are not remarkably different from those of the controls without type 2 diabetes. ${ }^{38}$

As expected, HOMA-IR, a marker of insulin resistance was higher among the cases with type 2 diabetes when compared with that of the controls. Insulin resistance is a core pathophysiological pathway in the development of type 2 diabetes mellitus. ${ }^{39}$ Also, this study showed a significantly higher 10-year cardiovascular risk score among Nigerians with type 2 diabetes when compared with those without type 2 diabetes. This is not surprising because type 2 diabetes is associated with a concurrent cluster of other cardiovascular risk factors such as obesity and hypertension, as demonstrated in this study and other previous studies. ${ }^{40,41}$ Again, insulin resistance has been suggested as a potential culprit behind this observation. ${ }^{40}$

Going by the results of this study, the prevalence of metabolic syndrome in people living with type 2 diabetes depends on the diagnostic criteria used. The frequency of metabolic syndrome, using the modified NCEP ATP III criteria, was $71.6 \%$. However, the frequency was slightly lower (65.7\%) when IDF criteria were applied. A previous study done among Nigerians with type 2 diabetes mellitus patients was $66.7 \% .{ }^{42}$ However, while the previous study used the conventional NCEP ATP III criteria, this present study used the modified NCEP ATP III criteria and this may account for the lower frequency in the previous study $(66.7 \%$ vs $71.6 \%)$ as it has been suggested that the modified criteria have a better performance. ${ }^{11}$ In support of this assertion, a study done in Ethiopia that used the Modified NCEP ATP III criteria, reported 
a prevalence of $70.1 \%$ which is quite similar to $71.6 \%$ found in this present study. The frequency of metabolic syndrome among type 2 diabetes mellitus patients diagnosed with the IDF criteria in this present study $(65.7 \%)$ is quite similar to what was found in a previous study in Nigeria that also used the IDF criteria (63.6\%). ${ }^{43}$

The prevalence of metabolic syndrome is significantly higher among patients with type 2 diabetes when compared with the general population whether the modified NCEP ATP III criteria $(71.6 \%$ vs $17.9 \% ; p<$ $0.0001)$ or the IDF criteria $(65.7 \%$ vs $10.4 \% ; p<0.0001)$ were used in making the diagnosis. A study done in Nigeria, using the IDF criteria for metabolic syndrome in the general population without type 2 diabetes mellitus, found a prevalence of $8.8 \%$ which is comparable to $10.4 \%$ documented in the present study. ${ }^{44}$ Another study done in Nigeria that used the NCEP ATP III criteria to diagnose metabolic syndrome in apparently healthy individuals not previously diagnosed with type 2 diabetes reported a prevalence rate of $12.1 \%$ which is lower than $17.9 \%$ found in this present study. This may be because while the previous study used the old NCEP ATP II criteria, the present study used the modified NCEP ATP III criteria which has been shown to have a better performance.

Using point biserial correlation, there was no statistically significant association between HOMA-IR (a marker of insulin resistance) and the presence of metabolic syndrome in type 2 diabetes mellitus whether the IDF criteria $(p=0.810)$ or the modified NCEP ATP III criteria $(p=0.909)$ were used. There is now a paradigm shift in what is believed to be the core component of metabolic syndrome. It is now thought that waist circumference, or truncal obesity, is more important than insulin resistance in the diagnosis of metabolic syndrome and this informed the IDF criteria which insist on the presence of increased waist circumference as a prerequisite for the diagnosis of metabolic syndrome. ${ }^{4}$ Interestingly, this present study found a significant association between metabolic syndrome, whether the modified NCEP ATP III or IDF criteria were used, and waist circumference $(p<0.0001)$. Previous studies have also demonstrated an association between metabolic syndrome and waist circumference. ${ }^{45,46}$

This study showed a significant association between metabolic syndrome and 10-year cardiovascular risk score only when the modified NCEP ATP III criteria were used in diagnosing metabolic syndrome $(p=$ 0.04) although the strength of the association was weak. This association was not demonstrable using the IDF criteria. This is in keeping with the hypothesis by previous researchers that the modified NCEP ATP III criteria have a better performance than the IDF criteria. ${ }^{11}$

This study was able to demonstrate an almost perfect agreement between using NCEP ATP II and IDF criteria in the diagnosis of metabolic syndrome among Nigerians with type 2 diabetes mellitus. $(K=0.862$; $p<0.0001$ ). It is still worthy of note that the IDF criteria missed $8.3 \%$ of the participants with type 2 diabetes which met the NCEP ATP criteria. However, neither NCEP ATP criteria $(k=0.143 ; p=0.116)$ nor the IDF criteria $(K=0.144 ; p=0.273)$ had a significant agreement with insulin resistance (using HOMA-IR). Again, this is in agreement with the hypothesis that insulin resistance is not a prerequisite in the diagnosis of metabolic syndrome. This study also found a fair but significant agreement between metabolic syndrome diagnosed with the modified NCEP ATP criteria $(K=0.213 ; p=0.029)$ and 
intermediate-to-high cardiovascular risk (using ASCVD risk categories) but this was not found with metabolic syndrome diagnosed with the IDF criteria. This suggests that the modified NCEP ATP III criteria predict cardiovascular risk much better than the IDF criteria.

\section{Limitations}

A larger sample size would be an advantage in this kind of study. The recruited cases with type 2 diabetes mellitus were already being managed in a multidisciplinary setting which may make some of the findings different from what is obtainable in the community.

\section{Conclusion}

Cardiovascular risk factors are commoner in people living with type 2 diabetes. The prevalence of metabolic syndrome among Nigerians with type 2 diabetes is slightly lower if IDF criteria are used than if the modified NCEP ATP III criteria are used. Using the modified NCEP ATP criteria to diagnose metabolic syndrome predicts cardiovascular risk better than using the IDF criteria. IDF criteria compares well with the modified NCEP ATP III criteria but it still misses out some people. The modified NCEP ATP III criteria appears to be a better diagnostic tool for metabolic syndrome among Nigerians with type 2 diabetes mellitus.

\section{Declarations}

Ethical approval and consent to participate: Ethical approval was granted by the ethical committee of the Institute Advanced Medical Research and Training with the reference number NHREC/05/01/2008a. The ethical approval number for the study was UI/EC/17/0284. Also, the recruited participants gave written informed consent to partake in the study.

Consent for publication: was taken from all participants.

Availability of data and material: Available, if required.

Funding: Self-funded

Competing interest: None.

Acknowledgement: None

\section{Abbreviations}

ACC - American College of Cardiology

AHA- American Heart Association 
ASCVD - Atherosclerotic Cardiovascular Disease

DBP - Diastolic blood pressure

EGIR - European Group for the Study of Insulin Resistance

FPG - Fasting plasma glucose

HbA1c - Glycated haemoglobin

HDL-C - High density lipoprotein-cholesterol

HOMA-IR - Homeostatic model of assessment of insulin resistance

IDF - International Diabetes Federation

NCEP ATP III - National Cholesterol Education Program on the detection, evaluation and treatment of high blood cholesterol in adults - adults treatment panel III

SBP - Systolic blood pressure

TG - Fasting plasma triglycerides

WHO - World Health Organization

\section{References}

1. P.M. Nilsson, J. Tuomilehto, L. Rydén. The metabolic syndrome - What is it and how should it be managed? Eur J Prev Cardiolog. 2019 Dec 1;26(2_suppl):33-46

2. G.M. Reaven. Banting lecture 1988. Role of insulin resistance in human disease. Diabetes. 1988 Dec;37(12):1595-607

3. V. Ormazabal, S. Nair, O. Elfeky, C. Aguayo, C. Salomon, F.A. Zuñiga, Association between insulin resistance and the development of cardiovascular disease. Cardiovascular Diabetology. 2018 Aug 31;17(1):122

4. R.M. Parikh, V. Mohan, Changing definitions of metabolic syndrome. Indian J Endocrinol Metab 16(1), 7-12 (2012)

5. B. Balkau, M.A. Charles, Comment on the provisional report from the WHO consultation. European Group for the Study of Insulin Resistance (EGIR). Diabet. Med. 16(5), 442-443 (1999 May)

6. E. Kassi, P. Pervanidou, G. Kaltsas, G. Chrousos, Metabolic syndrome: definitions and controversies. BMC Med. 5(1), 48 (2011 May) 9(

7. Expert Panel on Detection E and Treatment of High Blood Cholesterol in Adults, Executive Summary of the Third Report of the National Cholesterol Education Program (NCEP) Expert Panel on Detection, 
Evaluation, and Treatment of High Blood Cholesterol in Adults (Adult Treatment Panel III). JAMA 16(19), 2486-2497 (2001 May) 285(

8. C.M. Alexander, P.B. Landsman, S.M. Teutsch, S.M. Haffner. NCEP-Defined Metabolic Syndrome, Diabetes, and Prevalence of Coronary Heart Disease Among NHANES III Participants Age 50 Years and Older. Diabetes. 2003 May 1;52(5):1210-4

9. S.M. Grundy, H.B. Brewer, J.I. Cleeman, S.C. Smith, C. Lenfant, American Heart Association, et al. Definition of metabolic syndrome: Report of the National Heart, Lung, and Blood Institute/American Heart Association conference on scientific issues related to definition. Circulation. 2004 Jan 27;109(3):433-8

10. E.S. Ford, Prevalence of the Metabolic Syndrome Defined by the International Diabetes Federation Among Adults in the U.S. Diabetes Care. 2005 Nov 1;28(11):2745-9

11. F.M. Moy, A. Bulgiba, The modified NCEP ATP III criteria maybe better than the IDF criteria in diagnosing Metabolic Syndrome among Malays in Kuala Lumpur. BMC Public Health. 2010 Nov 6;10(1):678

12. T.A. Azeez, M.A. Osundina. Insulin resistance and non-alcoholic fatty liver disease: a review of the pathophysiology and the potential targets for drug actions | Azeez | Journal of the Medical Sciences (Berkala ilmu Kedokteran) [Internet]. [cited 2021 May 6]. Available from: https://jurnal.ugm.ac.id/bik/article/view/59594

13. C.K. Roberts, A.L. Hevener, R.J. Barnard, Metabolic Syndrome and Insulin Resistance: Underlying Causes and Modification by Exercise Training. Compr Physiol. 3(1), 1-58 (2013 Jan)

14. A. Lteif, K. Han, K. Mather, Obesity, Insulin Resistance, and the Metabolic Syndrome. Circulation. 2005 Jul 5;112(1):32-8

15. B. Singh, A. Saxena, Surrogate markers of insulin resistance: A review. World J Diabetes 15(2), 36-47 (2010 May) 1(

16. Udenze. Markers of insulin resistance and their performance in adult Nigerians with metabolic syndrome [Internet]. [cited 2021 May 14]. Available from: https://www.ijncd.org/article.asp? issn $=2468-8827$;year $=2019$; volume $=4$;issue $=2$; ppage $=43$;epage $=48$; aulast $=U d$ denze

17. J.D. Tune, A.G. Goodwill, D.J. Sassoon, K.J. Mather, Cardiovascular Consequences of Metabolic Syndrome. Transl Res 183, 57-70 (2017 May)

18. Q. Qiao, W. Gao, L. Zhang, R. Nyamdorj, J. Tuomilehto, Metabolic syndrome and cardiovascular disease. Ann. Clin. Biochem. 44(Pt 3), 232-263 (2007 May)

19. D.M. Lloyd-Jones, L.T. Braun, C.E. Ndumele, S.C. Smith, L.S. Sperling, S.S. Virani et al., Use of Risk Assessment Tools to Guide Decision-Making in the Primary Prevention of Atherosclerotic Cardiovascular Disease: A Special Report From the American Heart Association and American College of Cardiology. Circulation 18(25), e1162-e1177 (2019 Jun) 139(

20. V.P. Menon, F. Edathadathil, D. Sathyapalan, M. Moni, A. Don, S. Balachandran et al., Assessment of 2013 AHA/ACC ASCVD risk scores with behavioral characteristics of an urban cohort in India: 
Preliminary analysis of Noncommunicable disease Initiatives and Research at AMrita (NIRAM) study. Medicine. 95(49), e5542 (2016 Dec)

21. R. Anurhada, S. Hemacnandran, D. Ruma, The Waist Circumference Measurement: A Simple Method for Assessing the Abdominal Obesity. J Clin Diagn Res 6(9), 1510-1513 (2012 Nov)

22. L.P. Antoniolli, B.L. Nedel, T.C. Pazinato, L. de Andrade Mesquita, F. Gerchman. Accuracy of insulin resistance indices for metabolic syndrome: a cross-sectional study in adults. Diabetology \& Metabolic Syndrome. 2018 Aug 20;10(1):65

23. T.O. Akande, J.O. Adeleye, S. Kadiri, Insulin resistance in Nigerians with essential hypertension. African Health Sciences 5(3), 655-660 (2013 Sep) 13(

24. ASCVD Risk Estimator [Internet]. [cited 2021 Jun 3]. Available from: https://tools.acc.org/ldl/ascvd_risk_estimator/index.html\#!/calulate/estimator/

25. New Aspects of the Risk Assessment Guidelines: Practical Highlights, Scientific Evidence and Future Goals [Internet]. American College of Cardiology. [cited 2021 Jun 3]. Available from: http\%3a\%2f\%2fwww.acc.org\%2flatest-in-

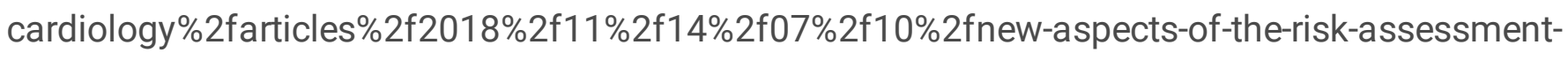
guidelines

26. M.L. McHugh, Interrater reliability: the kappa statistic. Biochem Med (Zagreb) 15(3), 276-282 (2012 Oct) 22(

27. E. Oda, Metabolic syndrome: its history, mechanisms, and limitations. Acta Diabetol. 49(2), 89-95 (2012 Apr)

28. Y. Akalu, Y. Belsti, Hypertension and Its Associated Factors Among Type 2 Diabetes Mellitus Patients at Debre Tabor General Hospital, Northwest Ethiopia. DMSO. 2020 May 13;13:1621-31

29. V. Tsimihodimos, C. Gonzalez-Villalpando, J.B. Meigs, E. Ferrannini. Hypertension and Diabetes Mellitus. Hypertension. 2018 Mar 1;71(3):422-8

30. E. Ferrannini, W.C. Cushman, Diabetes and hypertension: the bad companions. Lancet. 2012 Aug 11;380(9841):601-10

31. B.M.Y. Cheung, C. Li, Diabetes and hypertension: is there a common metabolic pathway? Curr Atheroscler Rep 14(2), 160-166 (2012 Apr)

32. G. Colussi, A. Da Porto, A. Cavarape, Hypertension and type 2 diabetes: lights and shadows about causality. J Hum Hypertens 34(2), 91-93 (2020 Feb)

33. P.N. Båvenholm, J. Kuhl, J. Pigon, A.K. Saha, N.B. Ruderman, S. Efendic, Insulin resistance in type 2 diabetes: association with truncal obesity, impaired fitness, and atypical malonyl coenzyme $A$ regulation. J Clin Endocrinol Metab. 88(1), 82-87 (2003 Jan)

34. N. Freemantle, J. Holmes, A. Hockey, S. Kumar, How strong is the association between abdominal obesity and the incidence of type 2 diabetes? Int J Clin Pract. 2008 Sep;62(9):1391-6

35. A.S. Al-Goblan, M.A. Al-Alfi, M.Z. Khan, Mechanism linking diabetes mellitus and obesity. Diabetes Metab Syndr Obes. 2014 Dec 4;7:587-91 
36. M. Laakso, Cardiovascular Disease in Type 2 Diabetes From Population to Man to Mechanisms. Diabetes Care. 33(2), 442-449 (2010 Feb)

37. C.L. Haase, A. Tybjærg-Hansen, B.G. Nordestgaard, R. Frikke-Schmidt. HDL Cholesterol and Risk of Type 2 Diabetes: A Mendelian Randomization Study. Diabetes. 2015 Sep 1;64(9):3328-33

38. D. Zheng, J. Dou, G. Liu, Y. Pan, Y. Yan, F. Liu et al. Association Between Triglyceride Level and Glycemic Control Among Insulin-Treated Patients With Type 2 Diabetes. The Journal of Clinical Endocrinology \& Metabolism. 2019 Apr 1;104(4):1211-20

39. T. Azeez, M. Osundina, Insulin resistance and non-alcoholic fatty liver disease: a review of the pathophysiology and the potential targets for drug actions. Journal of Diabetes and Obesity 2(1), 00 (2020 Nov) 6(

40. M.M. Adeva-Andany, J. Martínez-Rodríguez, M. González-Lucán, C. Fernández-Fernández, E. CastroQuintela, Insulin resistance is a cardiovascular risk factor in humans. Diabetes Metab Syndr 13(2), 1449-1455 (2019 Apr)

41. T.A. Azeez, Association between lipid indices and 10-year cardiovascular risk of a cohort of black Africans living with type 2 diabetes mellitus. Journal of Advances in Internal Medicine 14(1), 38-42 (2021 May) 10 (

42. C.U. Osuji, B.A. Nzerem, C.E. Dioka, E.I. Onwubuya. Metabolic syndrome in newly diagnosed type 2 diabetes mellitus using NCEP-ATP III, the Nnewi experience. Nigerian Journal of Clinical Practice. 2012 Oct 1;15(4):475

43. F.H. Puepet, A. Uloko, I.Y. Akogu, E. Aniekwensi, Prevalence of the metabolic syndrome among patients with type 2 diabetes mellitus in urban North-Central Nigeria. African Journal of Endocrinology and Metabolism 8(1), 12-14 (2009)

44. Muazu. Metabolic syndrome and its associated factors among apparently "healthy" adults residing in rural settlements in Dutse, Northwestern Nigeria: A community-based study [Internet]. [cited 2021 Jun 4]. Available from: https://www.jhrr.org/article.asp?issn=23942010;year=2019; volume=6;issue=3; ;page=95; ;page=101; ;ulast=Muazu;type=3

45. W. Shen, M. Punyanitya, J. Chen, D. Gallagher, J. Albu, X. Pi-Sunyer et al., Waist Circumference Correlates with Metabolic Syndrome Indicators Better Than Percentage Fat. Obesity (Silver Spring). 2006 Apr;14(4):727-36

46. M. Gierach, J. Gierach, M. Ewertowska, A. Arndt, R. Junik, Correlation between Body Mass Index and Waist Circumference in Patients with Metabolic Syndrome. ISRN Endocrinology 4;2014, e514589 (2014 Mar)

\section{Supplementary Files}

This is a list of supplementary files associated with this preprint. Click to download.

- formula.docx 